\title{
Efficacy of chemo-radiotherapy versus radiotherapy alone in the treatment of esophageal carcinoma
}

\author{
Kumar K.N. P. ${ }^{1}$, Ashwini L. ${ }^{2 *}$, Yadav I. ${ }^{3}$, Tyagi A. ${ }^{4}$, Lakshmaiah K. C. ${ }^{5}$ \\ DOI: https://doi.org/10.17511/ijmrr.2019.i05.05
}

${ }^{1}$ Pradeep Kumar K.N., Department of Radiation Oncologist, S.N. Medical College and Hospital, Agra, Uttar Pradesh, India.

2* Ashwini L., Department of Radiation Oncologist, S.N. Medical College and Hospital, Agra, Uttar Pradesh, India.

3 Indira Yadav, Department of Radiation Oncologist, S.N. Medical College and Hospital, Agra, Uttar Pradesh, India.

${ }^{4}$ Anuj Tyagi, Medical Physicist, , S.N. Medical College and Hospital, Agra, Uttar Pradesh, India.

5 Lakshmaiah K. C., Medical Oncologist, Department of Radiotherapy, S.N. Medical College and Hospital, Agra, Uttar Pradesh, India.

Background: The treatment of esophageal carcinoma may demand multiple approaches including combination of radiotherapy and chemotherapy, particularly cases which are considered unresectable, such as upper third esophageal cancers, locally advanced middle and lower third cancers. Methods: This was a prospective, randomized, open-label, single-center study conducted between December 2014 and July 2016. Patients of either sex aged more than 18 years with the confirmed diagnosis of previously untreated advanced esophageal carcinoma were included in the study. Eligible patients were randomized to receive one of the treatments (chemo-radiotherapy [cisplatin] or radiotherapy alone). Response criteria included dysphasia free survival (DySF), disease free survival (DFS), and overall survival (OS). Tolerability was also assessed. Results: A total of 31 patients (chemo-radiotherapy, $n=13$; radiotherapy alone, $n=18$ ) were enrolled in this study. At one year, the probability of remaining dysphagia free was $40 \%$ and $20 \%$, respectively for chemoradiotherapy and radiotherapy alone groups; and the probability of OS was $64 \%$ versus $21 \%$, respectively. The median DFS was 12 months and 5 months for chemo-radiotherapy and radiotherapy alone group, respectively. There were no significant differences in both the groups in EBRT, total treatment duration and duration of EBRT. No patient reported thrombocytopenia or nephrotoxicity. Conclusions: Concurrent chemo-radiotherapy with cisplatin can improve dysphasia and OS in patients with esophageal carcinoma.

Keywords: Chemotherapy, cisplatin, Esophageal neoplasm, Radiotherapy, Esophageal carcinoma

Corresponding Author

Ashwini L., Department of Radiation Oncologist, S.N. Medical College and Hospital, Agra, Uttar Pradesh, India.

Email: ashwini020191@gmail.com
How to Cite this Article

To Browse

Pradeep Kumar K.N., Ashwini L., Indira Yadav, Anuj Tyagi, Lakshmaiah K. C., Efficacy of chemoradiotherapy versus radiotherapy alone in the treatment of esophageal carcinoma. Int J Med Res Rev. 2019;7(5):370-379.

Available From

https://ijmrr.medresearch.in/index.php/ijmrr/article/ view/1082
Manuscript Received 2019-07-30

Conflict of Interest No
Review Round 1 2019-08-10

Funding

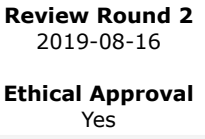

Review Round 3

Plagiarism X-checker

$$
4 \%
$$

Accepted 2019-08-22

Note

(c) 2019 by Pradeep Kumar K.N., Ashwini L., Indira Yadav, Anuj Tyagi, Lakshmaiah K. C. and Published by Siddharth Health Research and Social Welfare Society. This is an Open Access article licensed under a Creative Commons Attribution 4.0 International License https://creativecommons.org/licenses/by/4.0/ unported [CC BY 4.0].

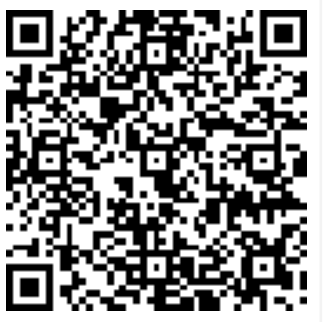




\section{Introduction}

Carcinoma of the esophagus is the seventh most common cancer worldwide, the sixth most common cause of cancer-related deaths worldwide [1], and fourth most common cause of cancer-related deaths in India [2]. In India, every year more than 47,000 new cases are reported of which around $90 \%$ of patients die [2].

The two major sub-types of esophageal carcinoma are esophageal squamous cell carcinoma (SCC) and adenocarcinoma. The history and incidence of these two types differ considerably. The predominant factors responsible for esophageal carcinoma are age, gender, race, environmental toxins, nutritional deficiency, alcohol consumption etc [3-6]. SCC affects the stratified squamous epithelial lining of the organ whereas adenocarcinoma affects columnar glandular cells that replace the squamous epithelium. Esophageal carcinoma is the most frequently occurring type having features like late presentation, late diagnosis, rapid progression, and low survival rates. An overall survival at 5 years ranged between $0 \%$ to $12 \%$ for patients treated with radiotherapy and $1 \%$ to $7 \%$ for patients treated with surgery [7-9].

Esophageal cancer is staged using the TNM system that implies the extent and presence of primary tumor, spread to lymph nodes and organs beyond lymph nodes. Common imaging modalities used in staging include computed tomography (CT), endoscopic ultrasound and positron emission tomography scans [10]. Studies suggest esophageal tumor length and diameter as important prognostic factors for nonsurgical $T$ staging in SCC patients undergoing definitive chemo-radiotherapy [11]. The treatment of esophageal carcinoma may demand multiple approaches including combination of radiotherapy and chemotherapy, particularly cases which are considered unresectable, such as upper third esophageal cancers, locally advanced middle and lower third cancers [2].

Diagnosis reveals majority of patients with advanced stage of SCC, hence surgery is not feasible. So, a non- surgical treatment modality like radiotherapy combined with chemotherapy is preferred but has poor response and survival rates $[12,13]$. Few recent meta-analyses have demonstrated that the use of chemo-radiotherapy has significant survival benefits in patients with esophageal carcinoma.
In a meta-analysis by Zhu et al, nine studies which included 1,135 cases (612 received concurrent chemoradiotherapy and 523 received radiotherapy alone) showed that patients who received concurrent chemoradiotherapy, demonstrated significantly higher overall response rate and reduced the risk of persistence and recurrence of disease [14-18].

Few Indian studies are reported in literature revealing the treatment outcomes of chemoradiotherapy. There is a need to assess an efficient and safe combination treatment modality to treat esophageal cancer.

The present paper report results of a prospective study that evaluated the efficacy of chemoradiotherapy versus radiotherapy alone for the treatment of patients with advanced esophageal SCC.

\section{Methods}

Study population- Patients of either sex aged more than 18 years with the confirmed diagnosis of previously untreated advanced esophageal carcinoma were included in the study.

Study design- This was a prospective, randomized, open-label, single-center study conducted between December 2014 and July 2016 at S.N. Medical College and Hospital, Agra, Uttar Pradesh, India. Eligible patients were randomized to receive one of the treatments (chemo-radiotherapy or radiotherapy alone).

Study group received external beam radiation therapy (EBRT) in two phases (phase 1-40 Gy/20\#/5\#/Week with two AP/PA fields; phase 2-20 Gy/10\#/5\#/Week with two posterior oblique fields) along with concurrent chemotherapy (cisplatin 35 $\mathrm{mg} / \mathrm{m} 2$ weekly for 5-6 cycles).

Control group received EBRT alone in two phases (phase 1 - $40 \mathrm{~Gy} / 20 \# / 5 \# /$ Week with two AP/PA fields; phase 2-20 Gy/10\#/5\#/Week with two posterior oblique fields).

Patients from study group received granisetron before and mannitol (20\%) after chemotherapy. On the day of chemotherapy, radiotherapy was given within 30 minutes of cisplatin infusion.

Inclusion criteria- The study included patients with histopathologically proven squamous cell carcinoma, Karnofsky performance status (KPS) $\geq 50$, hemoglobin $\geq 10 \mathrm{gm} \%$, total leucocyte count 
$\geq 4000 / \mathrm{mm} 3$, platelet count $\geq 100,000 / \mathrm{mm} 3$, serum creatinine $\leq 1.6 \mathrm{mg} / \mathrm{dL}$, and serum bilirubin $\leq 1$ $\mathrm{mg} / \mathrm{dL}$.

Exclusion criteria: Patients with adenocarcinoma, second primary neoplasm, and with recurrent disease were excluded from the study.

Ethical considerations: The institutional review board reviewed and approved the study protocol.

The study was conducted in accordance with the approved protocol, International Conference on Harmonization Good Clinical Practice (ICH-GCP) guidelines, and the ethical principles laid down in the Declaration of Helsinki 2013.

Each study participant provided written informed consent before participation in the study.

Response assessment and follow-up: Response criteria included dysphasia free survival (DySF), disease free survival (DFS), and overall survival (OS).

A patient was considered locally disease free only if the barium swallow at one month after completion of radiotherapy or at subsequent follow-up was smooth.

A local recurrence was scored if there was a positive pathological diagnosis (on endoscopic biopsy), evidence to suggest recurrence on a barium swallow, or signs and symptoms of mediastinal disease.

Dysphasia scores were recorded pre-and posttreatment and at every follow-up. Patients was considered dysphasia free only if solids or soft solids could be consumed without appreciable difficulty during or after treatment.

The dysphasia free status was terminated when patient reported any sustained inability to swallow solids or soft solids in spite of repeated attempts at dilatation when feasible.

Adverse events were recorded throughout the study duration using WHO criteria for acute and sub-acute toxicities. During follow-up period, ulcers, strictures and trachea-esophageal fistula were recorded along with recurrences, distant metastasis and second primaries.

Statistical analysis: There was no formal sample size calculation employed for this study. Statistical significance was computed using Chi square test, $t$ test and log rank test.
Patients alive or controlled at the time of reporting were considered censored observations. Patients lost to follow-up were handled according to the worst-case scenario and all endpoints were terminated when last seen.

All $p$ values were set at 0.05 and confidence intervals were calculated at the $95 \%$ level.

The DyFS, DFS and OS were measured from day one of treatment and analyzed from intent-to-treat (ITT) population, which included all randomized patients who received at least one dose of study medication.

\section{Results}

A total of 31 patients (chemo-radiotherapy, $n=13$; radiotherapy alone, $\mathrm{n}=18$ ) with advanced SCC of the esophagus were enrolled in this study. Overall, study groups were comparable, except for mean duration of dysphasia, which was longer in chemoradiation group (7.7 months vs. 3.3 months).

Among patients who received chemo-radiotherapy and radiotherapy alone the mean age was 57.3 years and 58.3 years, respectively. Overall, males were more in both the groups. Number of patients with stage III disease were higher in radiotherapy alone group; however, the number of patients with complete circumference involvement were higher in chemo-radiotherapy group.

A total of $93 \%$ of patients from chemo-radiotherapy group and $83 \%$ from radiotherapy along group had improvement or at least remained unchanged in their dysphasia after completion of treatment.

At one year, the probability of remaining dysphagia free was $40 \%$ and $20 \%$; and the median DyFS was $12 \%$ versus $5 \%$ (chemo-radiotherapy and radiotherapy alone groups, respectively; $p=0.05$ ). The duration of follow-up ranged from 2 to 17 months (median, 7.5 months) and a total of 11 patients died till the time of analysis.

At one year, the probability of OS was $64 \%$ versus $21 \%$ and the median was 13 months versus 6 months, for chemo-radiotherapy and radiotherapy alone groups, respectively. Among patients who received chemo-radiotherapy, 6 had local recurrence, 2 had distant metastasis, and 7 were living with the disease; however, among patients who received radiotherapy alone, 10 had local recurrence, 4 had distant metastasis, and 4 were living with the disease. 
A univariate analysis that assessed factors influencing DyFS, DFS, and OS is summarized in Table 2, which showed generally comparable results between the groups.

There were no significant differences in both the groups in EBRT, total treatment duration and duration of EBRT (Table 3). Seven patients received 6-7 cycles of chemotherapy, of which, two patients discontinued the treatment, one died due to disease progression and four patients reported grade 2-3 neutropenia. No patient reported thrombocytopenia or nephrotoxicity.

Among patients from chemo-radiotherapy group, seven patients reported anemia (grade $1, \mathrm{n}=3$; grade $2, \mathrm{n}=2$ and grade $3, \mathrm{n}=1)$; six patients reported leucopenia (grade $1, n=4$; grade $2, n=2$ ); and 12 patients reported emesis (grade $1, n=4$; grade $2, \mathrm{n}=3$; grade $3, \mathrm{n}=5$ ).

Table-1: Demographics and baseline characteristics.

\begin{tabular}{|l|l|l|}
\hline \multicolumn{1}{|c|}{ Parameters } & \multicolumn{1}{|c|}{$\begin{array}{c}\text { Chemo-radiotherapy } \\
\mathbf{N = 1 3}\end{array}$} & \multicolumn{1}{|c|}{$\begin{array}{c}\text { Radiotherapy alone } \\
\mathbf{N = 1 8}\end{array}$} \\
\hline $\begin{array}{l}\text { Age (years), mean } \\
\text { (SD) }\end{array}$ & $57.3(12.8)$ & $58.3(10.5)$ \\
\hline Age group & $5(38.5)$ & $11(61.1)$ \\
\hline$\leq 55$ years & $8(61.5)$ & $7(38.9)$ \\
\hline$>55$ years & $8(61.5)$ & $10(55.6)$ \\
\hline Sex, $\mathrm{n}(\%)$ & $5(38.5)$ & $8(44.4)$ \\
\hline Male & \\
\hline Female & \\
\hline KPS &
\end{tabular}

\begin{tabular}{|c|c|c|}
\hline 50 & $1(7.7)$ & $1(5.6)$ \\
\hline 60 & $1(7.7)$ & $2(11.1)$ \\
\hline 70 & $3(23.1)$ & $5(27.8)$ \\
\hline 80 & $4(30.8)$ & $6(33.3)$ \\
\hline 90 & $4(30.8)$ & $4(22.2)$ \\
\hline Weight loss (\%), Mean (SD) & $13.3(10.5)$ & $11.4(7.9)$ \\
\hline Hemoglobin (gm\%) & $12.1(1.6)$ & $12.6(1.8)$ \\
\hline Dysphasia duration (months), mean (SD) & $7.7(6.7)$ & $3.3(2.4)$ \\
\hline \multicolumn{3}{|l|}{ Dysphasia grade } \\
\hline To solids & $3(23.1)$ & $6(33.3)$ \\
\hline To soft solids & $6(46.2)$ & $7(38.9)$ \\
\hline To liquids & $3(23.1)$ & $5(27.8)$ \\
\hline Absolute & $1(7.7)$ & 0 \\
\hline \multicolumn{3}{|l|}{ Site } \\
\hline Upper & $3(23.1)$ & $6(33.3)$ \\
\hline Middle & $7(53.8)$ & $8(44.4)$ \\
\hline Lower & $3(23.1)$ & $4(22.2)$ \\
\hline Length $(\mathrm{cm})$, mean $(\mathrm{SD})$ & $7.7(1.9)$ & $8.5(3.4)$ \\
\hline \multicolumn{3}{|l|}{ Circumference } \\
\hline$<$ Complete & $7(53.8)$ & $5(27.8)$ \\
\hline Complete & $6(46.2)$ & $13(72.2)$ \\
\hline \multicolumn{3}{|l|}{ Features } \\
\hline Proliferative & $8(61.5)$ & $10(55.6)$ \\
\hline Ulcero-infiltrative & $5(38.5)$ & $7(38.9)$ \\
\hline Strictive & 0 & $1(5.6)$ \\
\hline \multicolumn{3}{|l|}{ Stage } \\
\hline $\mathrm{I}$ & 0 & $1(5.6)$ \\
\hline II & $10(76.9)$ & $11(61.1)$ \\
\hline III & $3(23.1)$ & $6(33.3)$ \\
\hline IV & 0 & 0 \\
\hline
\end{tabular}

Table-2: Summary of univariate analysis - factors influencing DyFS, DFS, and OS

\begin{tabular}{|c|c|c|c|c|c|c|}
\hline Variables $(\mathbf{N}=\mathbf{3 1})$ & Median DyFS (months) & P value & Median DFS (months) & $P$ value & Median os (months) & P value \\
\hline Age group & & 0.8 & & 0.24 & & \multirow[t]{3}{*}{0.89} \\
\hline$\leq 55$ years $(n=16)$ & 7 & & 0 & & 7.5 & \\
\hline$>55$ years $(n=15)$ & 9.5 & & 8.0 & & 9.5 & \\
\hline Sex, n (\%) & . & 0.58 & & 0.44 & & \multirow[t]{3}{*}{0.36} \\
\hline Male $(n=18)$ & 9.5 & & 8.0 & & 9.5 & \\
\hline Female $(n=13)$ & 5.0 & & 3.5 & & 5.0 & \\
\hline KPS & 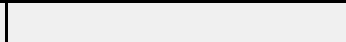 & 0.2 & 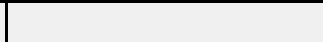 & 0.4 & & \multirow[t]{4}{*}{0.09} \\
\hline $50-60(n=5)$ & 5 & & 5 & & 5 & \\
\hline $70-80(n=18)$ & 4 & & 4 & & 6 & \\
\hline $90-100(n=8)$ & 11 & & 10 & & 15 & \\
\hline Weight loss (\%) & 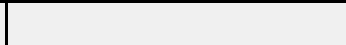 & 0.12 & 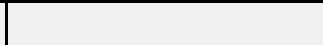 & 0.44 & & \multirow[t]{3}{*}{0.07} \\
\hline$\leq 10 \%(n=18)$ & 9.5 & & 8 & & 9.5 & \\
\hline$>10 \%(n=13)$ & 5 & & 3.5 & & 6.0 & \\
\hline Hemoglobin (gm\%) & & 0.4 & & 0.8 & & \multirow[t]{3}{*}{0.8} \\
\hline$\leq 10(n=5)$ & 5 & & 3.5 & & 6 & \\
\hline$>10(n=26)$ & 7.5 & & 8 & & 7.5 & \\
\hline
\end{tabular}


Kumar K. N. P. et al: Efficacy of chemo-radiotherapy versus radiotherapy

\begin{tabular}{|c|c|c|c|c|c|c|}
\hline Dysphasia duration (months) & & 0.82 & & 0.96 & & \multirow[t]{3}{*}{0.6} \\
\hline$\leq 3$ months $(n=18)$ & 6.5 & & 7.5 & & 7.5 & \\
\hline$>3$ months $(n=13)$ & 10 & & 10 & & 7 & \\
\hline Dysphasia grade & & 0.32 & & 0.3 & & \multirow[t]{5}{*}{0.3} \\
\hline To solids $(n=9)$ & 10 & & 10 & & 10 & \\
\hline To soft solids $(n=13)$ & 13 & & 13 & & 13 & \\
\hline To liquids $(n=8)$ & 6 & & 0 & & 7 & \\
\hline Absolute $(n=1)$ & 0 & & 0 & & 2 & \\
\hline Length $(\mathrm{cm})$ & & 0.8 & & 0.9 & & \multirow[t]{3}{*}{0.9} \\
\hline$\leq 7 \mathrm{~cm}(\mathrm{n}=18)$ & 9.5 & & 8.0 & & 9.5 & \\
\hline$>7 \mathrm{~cm}(\mathrm{n}=13)$ & 7.5 & & 3.5 & & 7.5 & \\
\hline \multirow[t]{2}{*}{ Circumference } & & - & & - & & \multirow[t]{3}{*}{0.02} \\
\hline & NR & & NR & & 17 & \\
\hline Complete $(n=19)$ & 6.5 & & 3.5 & & 7 & \\
\hline Features & & 0.3 & & 0.09 & & \multirow[t]{4}{*}{0.02} \\
\hline Proliferative $(n=18)$ & 9.5 & & 8 & & 9.5 & \\
\hline Ulcer infiltrative $(n=12)$ & 10 & & 10 & & 10 & \\
\hline Strictive $(n=1)$ & 0 & & 0 & & 3 & \\
\hline \multicolumn{6}{|l|}{ Stage } & \multirow[t]{4}{*}{-} \\
\hline$I+\operatorname{II}(n=22)$ & NR & & NR & & NR & \\
\hline III $(n=9)$ & 9.5 & & 8 & & 9.5 & \\
\hline IV $(n=0)$ & 0 & & 0 & & 3.5 & \\
\hline Radiotherapy duration & & 0.77 & & 0.90 & & \multirow[t]{3}{*}{0.43} \\
\hline$\leq 54$ days $(n=21)$ & 7.5 & & 7.5 & & 7.5 & \\
\hline$>54$ days $(n=10)$ & 5 & & 8 & & 7.5 & \\
\hline Protocol & & 0.4 & & 0.6 & & \multirow[t]{3}{*}{0.8} \\
\hline Radiotherapy alone $(\mathrm{n}=18)$ & 5 & & 3.5 & & 6 & \\
\hline Chemo-radiotherapy $(n=13)$ & 7.5 & & 8 & & 7.5 & \\
\hline
\end{tabular}

DFS, disease free survival; DyFS, dysphasia free survival; KPS, Karnofsky performance status; NR, not reached; OS, overall survival.

Table-3: Summary of study treatment and duration

\begin{tabular}{|c|c|c|c|}
\hline Parameters & $\begin{array}{l}\text { Chemo- } \\
\text { radiotherapy } \\
\qquad \mathbf{N}=13\end{array}$ & $\begin{array}{l}\text { Radiotherapy } \\
\text { alone } \mathbf{N}=\mathbf{1 8}\end{array}$ & $\mid \begin{array}{c}P \\
\text { value }\end{array}$ \\
\hline EBRT & & & \multirow[t]{3}{*}{0.5} \\
\hline$\leq 60 \mathrm{GY}$ & 10 & 16 & \\
\hline$>60 \mathrm{GY}$ & 3 & 2 & \\
\hline $\begin{array}{l}\text { Total treatment duration } \\
\text { (days), Mean (SD) }\end{array}$ & $57.9(9.2)$ & $58.3(9.7)$ & 0.5 \\
\hline $\begin{array}{l}\text { EBRT duration (days), Mean } \\
\text { (SD) }\end{array}$ & $56.8(6.8)$ & $55.3(11.2)$ & 0.5 \\
\hline \multicolumn{3}{|l|}{ Chemotherapy cycles } & \\
\hline $4-5$ & $6(46)$ & & \\
\hline 6-7 & $7(54)$ & & \\
\hline
\end{tabular}

Data shown as n (\%), unless otherwise specified. EBRT, external beam radiation therapy; SD, standard deviation.
Table-4: Summary of survival outcomes for patients who completed the treatment.

\begin{tabular}{|c|c|c|c|c|c|c|}
\hline \multirow{2}{*}{$\begin{array}{c}\text { Survival } \\
\text { probability }\end{array}$} & \multicolumn{2}{|c|}{ DyFS } & \multicolumn{2}{|c|}{ DFS } & \multicolumn{2}{|c|}{ os } \\
\hline & $\begin{array}{l}\text { CTRT } \\
N=13\end{array}$ & $\begin{array}{l}\text { RT } \\
N=18\end{array}$ & $\begin{array}{l}\text { CTRT } \\
N=13\end{array}$ & $\begin{array}{l}\mathrm{RT} \\
\mathrm{N}=18\end{array}$ & $\begin{array}{l}\text { CTRT } \\
N=13\end{array}$ & $\begin{array}{l}\mathrm{RT} \\
\mathrm{N}=18\end{array}$ \\
\hline 3 months & $88 \%$ & $78 \%$ & $75 \%$ & $56 \%$ & $87 \%$ & $94 \%$ \\
\hline 6 months & $79 \%$ & $59 \%$ & $75 \%$ & $49 \%$ & $87 \%$ & $63 \%$ \\
\hline 9 months & $79 \%$ & $40 \%$ & $75 \%$ & $35 \%$ & $74 \%$ & $42 \%$ \\
\hline 12 months & $47 \%$ & $20 \%$ & $62 \%$ & $24 \%$ & $74 \%$ & $21 \%$ \\
\hline Mean (months) & 10.9 & 7.8 & 10.3 & 6.7 & 11.8 & 8.8 \\
\hline $95 \%$ CI & 8.4-13.5 & $5-10.5$ & $7.2-13.4$ & $3.4-10$ & $9.4-14.3$ & $\begin{array}{l}6.2- \\
11.3\end{array}$ \\
\hline Median (months) & 12 & 7 & 13 & 3.5 & 13 & 7 \\
\hline $95 \%$ CI & $9.7-14$ & $4-10$ & 0 & $0-11.5$ & $6.4-19.6$ & $5.2-8.8$ \\
\hline Events & $6 / 13$ & $12 / 18$ & $6 / 13$ & $12 / 18$ & $5 / 13$ & $11 / 18$ \\
\hline $\mathrm{P}$ value & \multicolumn{2}{|l|}{0.07} & \multicolumn{2}{|l|}{0.07} & \multicolumn{2}{|l|}{0.06} \\
\hline \multicolumn{7}{|c|}{$\begin{array}{l}\text { CI, confidence interval; CTRT, chemo-radiotherapy; DFS, disease free } \\
\text { survival; DyFS, dysphasia free survival; OS, overall survival; RT, } \\
\text { radiotherapy. }\end{array}$} \\
\hline
\end{tabular}

Overall, the morbidity during follow-up period was comparable $(p>0.05)$ between the groups 
(Ulcerations $[n=6$ vs. $n=4] ;$ strictures $[n=6$ vs. $\mathrm{n}=10]$; fistulae $[\mathrm{n}=2$ vs. $\mathrm{n}=1]$; and retrosternal pain/epigastric discomfort $[n=5$ vs. $n=2]$; dilatation/stunting procedure $[n=3$ vs. $n=2]$; respectively for chemo-radiotherapy and radiotherapy alone group).

Table 4 summarizes survival outcomes for patients who completed the treatment, which demonstrates no significant difference between the groups. However, the outcomes were slightly higher in chemo-radiotherapy group than radiotherapy alone group.

\section{Discussion}

Esophageal carcinoma can be managed by endoscopic mucosal resection, surgery, chemotherapy, radiotherapy, palliative therapy or a combination of these modalities depending on the stage and extent of the disease. Concurrent chemoradiotherapy or radiotherapy alone are generally recommended in patients with upper or middle third carcinomas, inoperable cases, and in locally advanced cases. A meta-analysis by Ma et al, stated that concurrent chemo-radiotherapy significantly improves progression-free survival and OS in patients with esophageal cancer compared to surgery [19].

Another meta-analysis by Sun et al, investigated the safety and efficacy of treatment modalities used in concurrent radiotherapy. It revealed that concurrent therapy increased adverse reactions rather than patient survival [20]. In this prospective randomized study, we aimed to compare the efficacy of chemoradiotherapy with radiotherapy alone in the treatment of locally advanced esophageal squamous cell carcinoma.

The present study was conducted in a teaching hospital in India, where patients are treated using concurrent chemo-radiotherapy or radiotherapy alone based on physicians' preference and disease condition. This study was a part of postgraduate thesis at a single center and hence was limited by the study period that could have resulted in smaller sample size.

Both the groups showed male preponderance and comparable mean age. Smith et al, conducted a study to determine the efficacy of chemo-radiation in comparison to radiation alone that showed male predominance and a longer median survival with chemoradiation (14.8 months) compared to patients with radiation therapy alone (9.2 months) [21].
Lyu et al, reported a similar study having male predominance, age between 18-75 years, majority of patients with upper thoracic tumor location and having stage $4 \mathrm{SCC}$. It was observed that concurrent chemotherapy was better and had manageable adverse events [22].

The EBRT included in this study were 40 Gy/20\#/5\#/week with two AP/PA fields for phase 1 and $20 \mathrm{~Gy} / 10 \# / 5 \# /$ week with two posterior oblique fields for phase 2. A previous study, which compared two radiotherapy protocols ( $50 \mathrm{~Gy}$ in 25 fractions over 5 weeks and $35 \mathrm{~Gy}$ in 15 fractions over 3 weeks) in inoperable SCC of the esophagus showed dysphagia relief in $75 \%$ and $49 \%$ of patients; and the probability of survival at 1, 2 and 5 years was $35.8 \%$ versus $34.8 \%, 13.9 \%$ versus $14.5 \%$ and $10 \%$ versus $0 \%$, respectively [23].

Several studies have demonstrated the efficacy of chemo-radiotherapy in the treatment of esophageal carcinoma. Basis behind the addition of chemotherapy to radiotherapy is to potentiate the effects of radiotherapy to local disease and to decrease the incidence of distant metastasis. Hence, survival outcomes are expected to vary both as a function of selection of patients and the intensity of chemoradiation. In this study, one patient from chemo-radiotherapy and two patients from radiotherapy alone group developed distant metastasis.

A recent meta-analysis that included nine studies, demonstrated that concurrent use of chemoradiotherapy significantly improved $O S$, reduced the risk of persistence and recurrence, but increased the occurrence of acute toxic effects, compared with radiotherapy alone [14]. A previous study from India that included 125 patients with unresectable SCC of the esophagus, showed $57.6 \%, 38.9 \%$ and $24.8 \%$ versus $32.3 \%, 22.8 \%$ and $13.7 \%$ OS at 1,2 , and 5 year, for chemo-radiotherapy and radiotherapy alone groups, respectively [24].

Uthors concluded that the addition of concurrent cisplatin to radiotherapy can improve survival with manageable acute and late morbidity [23]. Another study by Ruler et al, showed median OS of 13.1 months (95\% CI 4.7-21.5 months) and a 2-year OS of $30 \%$ ( $95 \%$ CI $18 \%-42 \%$ )[24]. In this study the 1year OS was slightly higher (74\%) in chemoradiotherapy group and was slightly lower $(21 \%)$ for radiotherapy alone group.

Patients with esophageal carcinoma mainly present with dysphagia; 
However, to our knowledge limited data is available regarding its relief. In a previous study, patients receiving fluorouracil and cisplatin showed improvement from baseline to week 15 (37.6 versus 29.9, $p=0.047)[25]$.

Another retrospective study that included patients $(\mathrm{N}=66)$ with esophageal carcinoma and treated with chemoradiotherapy (carboplatin and paclitaxel) demonstrated that around $70 \%$ of patients had relief of dysphagia [26]. In the present study, dysphasia relief was achieved in $64 \%$ and $48 \%$ of patients from chemo-radiotherapy and radiotherapy alone group, respectively. The median DFS was 12 months and 5 months for chemo-radiotherapy and radiotherapy alone group, respectively.

Chemotherapy compliance was observed in $76 \%$ of patients. Overall, both treatments were generally tolerable with no new safety signals. Chemotherapy associated acute toxicities were also consistent with the previous study [24]. There were no reports of thrombocytopenia or nephrotoxicity. None of the patients from chemo-radiotherapy group reported grade 4 toxicity. The worst chemotherapy toxicities observed were grade 3 neutropenia and grade 3 emesis.

Previous studies suggest that preoperative chemoradiotherapy for esophageal SCC significantly increased patients' risk of cardiopulmonary complication [27]. As per European Society for Medical Oncology (ESMO) recommendations, the patients unable or unwilling to undergo surgery, a combined chemo-radiotherapy is superior to radiation therapy alone and four courses of cisplatin/5-Flourouracil combined with radiation doses of $50.4 \mathrm{~Gy}$ in fractions of $1.8 \mathrm{~Gy}$ are regarded as standard for definitive chemo-radiotherapy [28].

Intensity modified radiotherapy (IMRT) with concurrent chemotherapy has demonstrated reduction inradiation-induced toxicities, enhanced local control and improved long-term survival combining [29]. Literature has documented studies that have confirmed patient outcomes favoring chemoradiation compared to radiation alone [30].

This study with a small sample size showed concurrent chemo-radiotherapy with cisplatin can improve dysphasia and OS in patients with esophageal carcinoma; however, the difference was not statistically significant. Future research may be needed to corroborate these outcomes.

\section{Conclusion}

This prospective study implies better outcomes with concurrent chemo-radiotherapy in patients with esophageal cancer. The overall survival of patients is improved with tolerable side effects.

\section{What the study adds to the existing knowledge?}

Dose escalation with concurrent chemoradiation feasible with good compliance and response rates. This study with a small sample size showed concurrent chemoradiation with cisplatin can improve dysphagia and overall survival in patients.

\section{Author's contribution}

Dr. Pradeep Kumar $\mathbf{K} \mathbf{N}$ and Dr. Ashwini L. contributed to the concept of the study, study design, data collection, interpretation, review of the literature, writing and review of the manuscript.

Dr. Pradeep Kumar K N. additionally contributed to the statistical analysis. All authors met ICMJE authorship criteria.

\section{Acknowledgement}

The authors thank Dr. A.K. Arya (Professor and Guide) for his support and guidance in completing the present study.

\section{Reference}

01. Bray F, Ferlay J, Soerjomataram I, Siegel RL, Torre LA, Jemal A. Global cancer statistics 2018GLOBOCAN estimates of incidence and mortality worldwide for 36 cancers in 185 countries. CA Cancer J Clin. 2018;68(6)394-424. doi:10.3322/caac.21492 [Crossref]

02. Samarasam I. Esophageal cancer in IndiaCurrent status and future perspectives. Int $\mathrm{J}$ Adv Med Health Res. 2017;4(1)5-10. doi: 10.4103/ijamr.ijamr_19_17 [Crossref]

03. Dawsey SM, Lewin KJ, Wang GQ, Liu FS, Nieberg RK, Yu $Y$, et al. Squamous esophageal histology and subsequent risk of squamous cell carcinoma of the esophagus- A prospective follow-up study from Linxian, China. Cancer. $1994 ; 74(6) 1686-1692$.

[Crossref] 
04. Dawsey SM, Lewin KJ, Liu FS, Wang GQ, Shen Q. Esophageal morphology from Linxian, ChinaSquamous histologic findings in 754 patients. Cancer. 1994;73(8)2027-2037.

[Crossref]

05. Yu G, Chen G, Huang B, Shao W, Zeng G. Effect of early enteral nutrition on postoperative nutr itional status and immune function in elderly patients with esophageal cancer or cardiac cancer. Chin J Cancer Res. 2013;25(3)299-305. doi: $10.3978 /$ j.issn.1000-9604.2013.06.01 [Crossref]

06. Brown LM, Hoover RN, Greenberg RS, Schoe nberg JB, Schwartz AG, Swanson GM, et al. Are racial differences in squamous cell esophageal cancer explained by alcohol and tobacco use?. J Natl Cancer Inst. 1994;86(17)1340-1345.

doi: $10.1093 /$ jnci/86.17.1340 [Crossref]

07. al-Sarraf M, Martz K, Herskovic A, Leichman L, Brindle JS, Vaitkevicius VK, et al. Progress report of combined chemoradiotherapy versus radiotherapy alone in patients with esophageal cancer- An intergroup study. J Clin Oncol. $1997 ; 15(1) 277-284$.

[Crossref]

08. Berger AC, Farma J, Scott WJ, Freedman G, Wei ner $L$, Cheng JD, et al. Complete response to ne oadjuvant chemoradiotherapy in esophageal car cinoma is associated with significantly improved survival. J Clin Oncol. 2005;23(19)4330-4337. doi: 10.1200/JCO.2005.05.017 [Crossref]

09. Earlam R, Cunha-Melo JR. Esophageal squamous cell carcinomas- II, A critical view of radiotherapy. $\mathrm{Br}$ J Surg. 1980;67(7)457-461. doi: 10.1002/bjs.1800670702 [Crossref]

10. Napier KJ, Scheerer M, Misra S. Esophageal can cer- A Review of epidemiology, pathogenesis, staging workup and treatment modalities. World J Gastrointest Oncol. 2014;6(5)112-120.

doi: 10.4251/wjgo.v6.i5.112 [Crossref]

11. Xu H, Wu S, Luo H, Chen C, Lin L, Huang H, Xue $R$. Prognostic value of tumor length and diameter for esophageal squamous cell cancer patients treated with definitive (chemo) radiotherapy- Potential indicators for nonsurgical T staging. Cancer Med. 2019.

doi: 10.1002/cam4.2532 [Crossref]
12. Cooper JS, Guo MD, Herskovic A, Macdonald JS, Martenson JA Jr, Al Sarraf $M$, et al. Chemoradiotherapy of locally advanced esophageal cancer- Long term follow up of a prospective randomized trial (RTOG 85 01)Radiation Therapy Oncology Group. JAMA. $1999 ; 281(17) 1623-1627$.

doi: 10.1001/jama.281.17.1623 [Crossref]

13. Zhao KL, Liu G, Jiang GL, Wang $Y$, Zhong LJ, Wang $Y$, et al. Association of hemoglobin level with morbidity and mortality of patients with locally advanced esophageal carcinoma undergoing radiotherapy a secondary analysis of three consecutive clinical phase III trials. Clin Oncol (R Coll Radiol). 2006;18(8)621-627. doi: 10.1016/j.clon.2006.04.015 [Crossref]

14. Zhu LL, Yuan L, Wang H, Ye L, Yao GY, Liu C, et al. A meta-analysis of concurrent chemoradiotherapy for advanced esophageal cancer. PLoS One. 2015;10(6)e0128616.

doi: $10.1371 /$ journal.pone.0128616 [Crossref]

15. Montagnani $F$, Fornaro $L$, Frumento $P$, Vivaldi $C$, Falcone A, Fioretto L. Multimodality treatment of locally advanced squamous cell carcinoma of the esophagus- A comprehensive review and network meta-analysis. Crit Rev Oncol Hematol. 2017;114;24-32.

doi: $10.1016 /$ j.critrevonc.2017.03.024 [Crossref]

16. Wang $D B$, Sun $Z Y$, Deng $L M$, Zhu DQ, Xia HG, Zhu PZ. Neoadjuvant chemoradiotherapy improving survival outcomes for esophageal carcinoma- an updated meta-analysis. Chin Med J (Engl). 2016;129(24)2974-2982. doi: 10.4103/0366-6999.195464 [Crossref]

17. Liu B, Bo $Y$, Wang $K$, Liu $Y$, Tang $X$, Zhao $Y$, et al. Concurrent neoadjuvant chemoradiotherapy coul d improve survival outcomes for patients with es ophageal cancer- a meta-analysis based on rand om clinical trials. Oncotarget. 2017;8(12)20410

-17. doi: 10.18632/oncotarget.14669 [Crossref]

18. Li F, Li T, Liu L, Lv J, Song Y, Li C, et al. Con current versus sequential chemoradiotherapy for esophageal cancer among Chinese population- a meta-analysis. Tumori. 2015;101(4)353-359.

doi: $10.5301 /$ tj.5000314 [Crossref] 
19. Ma HF, Lv GX, Cai ZF, Zhang DH. Comparison of the prognosis of neoadjuvant chemoradiotherapy treatment with surgery alone in esophageal carcinoma- a metaanalysis. Onco Targets Ther. 2018;11;34413447.

doi: $10.2147 / 0 T T . S 145063 \quad$ [Crossref]

20. Sun L, Zhao F, Zeng Y, Yi C. Risks and Benefits of Multimodal Esophageal Cancer Treatments- A Meta-Analysis. Med Sci Monit. 2017;23;889910.

doi: $10.12659 / M S M .903328$ [Crossref]

21. Smith TJ, Ryan LM, Douglass HO Jr, Haller DG, Dayal Y, Kirkwood J, et al. Combined chemoradio-therapy vs radiotherapy alone for early stage squamous cell carcinoma of the esophagus- a study of the Eastern Cooperative Oncology Group. Int J Radiat Oncol Biol Phys. 1998;42(2)269-276.

doi: $10.1016 / \mathrm{S} 0360-3016(98) 00232-6 \quad$ [Crossref]

22. Lyu J, Li T, Wang Q, Li F, Diao P, Liu L, Li C, Lang J. Outcomes of concurrent chemoradiotherapy versus chemotherapy alone for stage IV esophageal squamous cell carcinoma- a retrospective controlled study. Radiat Oncol. 2018;13(1)233.

doi: $\quad 10.1186 / \mathrm{s} 13014-018-1183-y \quad$ [Crossref]

23. Datta NR, Kumar S, Nangia S, Hukku S, Ayyagari S. A non-randomized comparison of two radiotherapy protocols in inoperable squamous cell carcinoma of the oesophagus. Clin Oncol (R Coll Radiol). 1998;10(5)306-312. doi: 10.1016/s0936-6555(98)80083-6 [Crossref]

24. Kumar S, Dimri K, Khurana R, Rastogi N, Das $\mathrm{KJ}$, Lal P. A randomised trial of radiotherapy compared with cisplatin chemo-radiotherapy in patients with unresectable squamous cell cancer of the esophagus. Radiother Oncol. 2007;83(2)139-147.

doi: $\quad 10.1016 /$ j.radonc.2007.03.013 [Crossref]
25. Bascoul- Mollevi C, Gourgou S, Galais MP, Raoul $\mathrm{JL}$, Bouché O, Douillard JY, et al. Health-related quality of life results from the PRODIGE 5/ACCORD 17 randomized trial of FOLFOX versus fluorouracil-cisplatin regimen in oesophageal cancer. Eur J Cancer. 2017;84;239249.

doi: 10.1016/j.ejca.2017.07.038 [Crossref]

26. Ruler MA, Peters FP, Slingerland $M$, Fiocco $M$, Grootenboers DA, Vulink AJ, et al. Clinical outcomes of definitive chemoradiotherapy using carboplatin and paclitaxel in esophageal cancer. Dis Esophagus. 2017;30(4)1-9.

doi: $10.1093 /$ dote/dow033 [Crossref]

27. Pischik VG. Editorial comments for neoadjuvant chemo-radiotherapy in the treatment of locally advanced squamous cell esophageal cancer. J Thorac Dis. 2018;10(11)5979-5981.

doi: $10.21037 /$ jtd.2018.10.81 [Crossref]

28. Lordick F, Mariette C, Haustermans $\mathrm{K}$, Obermannová R, Arnold D. Oesophageal Cancer- ESMO Clinical Practice Guidelines. Ann Oncol. 2016;27(suppl 5)v50-v57.

[Crossref]

29. Chen $M$, Li $X$, Chen $Y$, Liu $P$, Chen $Z$, Shen $M$, et al. Proposed revision of the 8th edition AJCC clinical staging system for esophageal squamous cell cancer treated with definitive chemo-IMRT based on CT imaging. Radiat Oncol. $2019 ; 14(1) 54$.

doi: $\quad 10.1186 / \mathrm{s} 13014-019-1258-4 \quad$ [Crossref]

30. Welsh J, Amini A, Likhacheva A, Erasmus JJ, Gomez D, Davila $M$, et al. Update- modern approaches to the treatment of localized esophageal cancer. Curr Oncol Rep. $2011 ; 13(3) 157-167$.

doi: $\quad 10.1007 / \mathrm{s} 11912-011-0158-z \quad$ [Crossref] 